See Article page 28.

\section{Commentary: Hybrid only for a few}

\section{Francisco Diniz Affonso da Costa, MD}

Despite surgical and technological advances, repair of thoracoabdominal aortic aneurysms (TAAAs), either by open surgery, total endovascular, or a hybrid approach, is still associated with considerable morbidity and mortality. ${ }^{1,2}$ In this issue of the JTCVS Techniques, Tanaka and colleagues ${ }^{3}$ have made an objective and concise overview on the advantages, drawbacks, and limitations of each of those methods.

It has been demonstrated that when performed in highvolume reference centers, open surgical repair is associated with diminished late complications and better patient outcomes, and as such, should be the preferred alternative in younger patients with no important comorbidities, and in those with connective tissue disorders and chronic dissections. ${ }^{1}$ Unfortunately, a significant proportion of patients with TAAA are elderly, with important baseline associated conditions and variable degrees of organ dysfunction, with the corresponding increased surgical risks. Under these circumstances, less-invasive procedures may be desirable and in experienced hands have been associated with lower operative and short-term mortality and decreased hospital costs. ${ }^{4}$

The use of custom-made fenestrated/branched grafts is being tested in clinical trials and represent the most promising alternative for total endovascular TAAA repair. At present, these grafts take several weeks to be customized, are costly, and are performed only in selected centers. ${ }^{2}$ Chimney/parallel grafts and hybrid debranching interventions have also been proposed as less-invasive alternatives for TAAA repair. ${ }^{5,6}$ The former, although readily available, has some anatomic limitations, somewhat limited to lessextensive aneurysms and a relatively high incidence of type 1 endoleak. The hybrid procedure, by avoiding a thoracotomy, may be considered less invasive, but results in nonphysiological flow to the visceral arteries and is

From the Department of Cardiovascular Surgery, Instituto de Neurologia e Cardiologia de Curitiba - INC Cardio, Curitiba, Brazil.

Disclosures: The author reported no conflicts of interest.

The Journal policy requires editors and reviewers to disclose conflicts of interest and to decline handling or reviewing manuscripts for which they may have a conflict of interest. The editors and reviewers of this article have no conflicts of interest.

Received for publication Aug 16, 2021; revisions received Aug 16, 2021; accepted for publication Aug 20, 2021; available ahead of print Aug 26, 2021.

Address for reprints: Francisco Diniz Affonso da Costa, MD, Instituto de Neurologia e Cardiologia de Curitiba - INC-Cardio, Rua Henrique Coelho Neto, 55, 82200-

120 Curitiba, Paraná, Brazil (E-mail: fcosta13@mac.com).

JTCVS Techniques 2021;10:36

2666-2507

Copyright (C) 2021 The Author(s). Published by Elsevier Inc. on behalf of The American Association for Thoracic Surgery. This is an open access article under the CC BY-NC-ND license (http://creativecommons.org/licenses/by-nc-nd/4.0/).

https://doi.org/10.1016/j.xjtc.2021.08.036

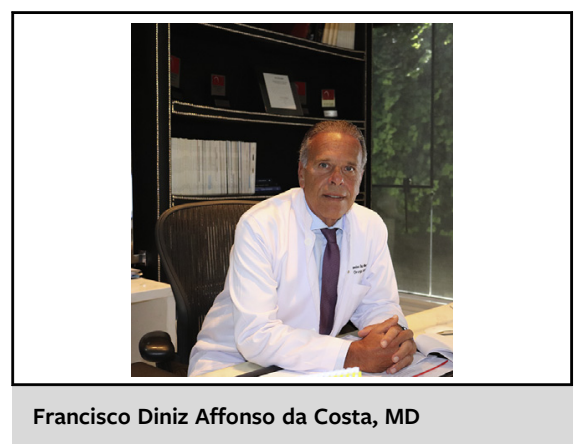

CENTRAL MESSAGE

Debranching, chimneys, and snorkels are alternative methods for thoracoabdominal aneurysm repair but should be employed only in high-risk patients or if custom grafts are not available.

associated with similar morbidity and mortality rates when compared with the classical open repair. It may be advantageous, however, in selected high-risk patients with obesity and chronic obstructive pulmonary disease.

From the aforementioned considerations, it becomes clear why the experienced group from Houston ${ }^{3}$ reserves the alternative hybrid procedures or the chimney/parallel grafts for only a few selected groups of patients who are not candidates for either an open surgical repair or a total endovascular procedure with custom-made grafts. On the contrary, it should not be forgotten that worldwide, just a minority of patients will be operated in reference aortic centers, and alternative options may represent a viable form of treatment for them.

\section{References}

1. Moulakakis KG, Karaolanis G, Antonopoulos CN, Kakisis J, Klonaris C, Preventza O, et al. Open repair of thoracoabdominal aortic aneurysms in experienced centers. J Vasc Surg. 2018;68:634-45.e12.

2. Fernandez CC, Sobel JD, Gasper WJ, Vartanian SM, Reilly LM, Chuter TA, et al. Standard off-the-shelf versus custom-made multibranched thoracoabdominal aortic stent grafts. J Vasc Surg. 2016;63:1208-15.

3. Tanaka A, Oderich GS, Estrera AL. Total abdominal debranching hybrid thoracoabdominal aortic aneurysm repair versus chimneys and snorkels. J Thorac Cardiovasc Surg Tech. 2021;10:28-33.

4. Locham S, Dakour-Aridi H, Nejim B, Dhaliwal J, Alshwaily W, Malas M. Outcomes and cost of open versus endovascular repair of intact thoracoabdominal aortic aneurysm. J Vasc Surg. 2018;68:948-55.e1.

5. Pecoraro F, Veith FJ, Puippe G, Amman-Vesti B, Bettex D, Rancic Z, et al. Midand longer-term follow up of chimney and/or periscope grafts and risk factors for failure. Eur J Vasc Endovasc Surg. 2016;51:664-73.

6. Yang G, Zhang M, Muzepper M, Du X, Wang W, Liu C, et al. Comparison of physician-modified fenestrated/branched stent-grafts and hybrid visceral debranching plus stent-graft placement for complex thoracoabdominal aortic aneurysm repair. J Endovasc Ther. 2020;27:749-56. 